\title{
Incidence of post-traumatic pneumonia in poly-traumatized patients: identifying the role of traumatic brain injury and chest trauma
}

\author{
Martijn Hofman $^{1}$ (D) Hagen Andruszkow ${ }^{1} \cdot$ Philipp Kobbe $^{1} \cdot$ Martijn Poeze $^{2} \cdot$ Frank Hildebrand $^{1}$
}

Received: 18 March 2019 / Accepted: 24 June 2019 / Published online: 3 July 2019

(c) Springer-Verlag GmbH Germany, part of Springer Nature 2019

\begin{abstract}
Purpose Traumatic brain injury (TBI) and chest trauma are common injuries in severely injured patients. Both entities are well known to be associated with severe post-traumatic complications, including pneumonia, a common complication with a significant impact on the further clinical course. However, the relevance of TBI, chest trauma and particularly their combination as risk factors for the development of pneumonia and its impact on outcomes are not fully elucidated.

Methods A retrospective analysis of poly-traumatized patients treated between 2010 and 2015 at a level I trauma centre was performed. Inclusion criteria were: Injury Severity Score $\geq 16$ and age $\geq 18$ years. TBI and chest trauma were classified according to the Abbreviated Injury Scale. Complications (i.e. acute respiratory distress syndrome (ARDS), multi-organ dysfunction syndrome (MODS) and pneumonia) were documented by a review of the medical records. The primary outcome parameter was in-hospital mortality.

Results Over the clinical course, $19.9 \%$ of all patients developed pneumonia, and in-hospital mortality was $25.3 \%$. Pneumonia (OR 5.142, $p=0.001$ ) represented the strongest independent predictor of in-hospital mortality, followed by the combination of chest injury and TBI (OR 3.784, $p=0.008)$ and TBI (OR 3.028, $p=0.010)$. Chest injury alone, the combination of chest injury and TBI, and duration of ventilation were independent predictors of pneumonia [resp. OR $4.711(p=0.004)$, OR 4.193 $(p=0.004)$, OR $1.002(p<0.001)]$.

Conclusions Chest trauma alone and especially its combination with TBI represent high-risk injury patterns for the development of pneumonia, which forms the strongest predictor of mortality in poly-traumatized patients.
\end{abstract}

Keywords TBI $\cdot$ Chest injury $\cdot$ Poly-trauma $\cdot$ Pneumonia $\cdot$ Mortality

Martijn Poeze and Frank Hildebrand jointly supervised this work.

Martijn Hofman

mhofman@ukaachen.de

Hagen Andruszkow

handruszkow@ukaachen.de

Philipp Kobbe

pkobbe@ukaachen.de

Martijn Poeze

m.poeze@mumc.nl

Frank Hildebrand

fhildebrand@ukaachen.de

1 Department of Orthopedic Trauma and Reconstructive Surgery, University of Aachen Medical Center,

Pauwelsstraße 30, 52074 Aachen, Germany

2 Department of Surgery, Division of Trauma Surgery, Maastricht University Medical Center, P. Debyelaan 25, 6229 HX Maastricht, The Netherlands

\begin{tabular}{|c|c|}
\hline \multicolumn{2}{|c|}{ Abbreviations } \\
\hline AIS & Abbreviated injury scale \\
\hline ARDS & Acute respiratory distress syndrome \\
\hline $\operatorname{ATLS}^{\circledR}$ & Advanced Trauma Life Support ${ }^{\circledR}$ \\
\hline GCS & Glasgow Coma Scale \\
\hline ICU & Intensive care unit \\
\hline MODS & Multi-organ dysfunction syndrome \\
\hline NISS & New injury severity score \\
\hline OR & Odds ratio \\
\hline $\mathrm{paO}_{2} / \mathrm{FiO}_{2}$ & $\begin{array}{l}\text { Partial pressure of oxygen/fraction of inspired } \\
\text { oxygen }\end{array}$ \\
\hline SD & Standard deviation \\
\hline SIRS & Systemic inflammatory response syndrome \\
\hline SOFA & Sequential organ failure assessment \\
\hline SPSS & Statistical package for the social sciences \\
\hline TBI & Traumatic brain injury \\
\hline VAP & Ventilator-associated pneumonia \\
\hline
\end{tabular}




\section{Introduction}

Traumatic brain injury (TBI) and chest trauma represent the most common injuries in severely injured patients, and there is a high co-incidence of these injury patterns $[1,2]$. TBI is a serious condition $[3,4]$ that can be caused by both the primary traumatic impact and secondary factors, such as hypoxia, hypotension, anaemia, hypo- or hyperglycaemia and inflammatory processes [5-7]. TBI is frequently associated with a prolonged stay on the intensive care unit (ICU), a high incidence of disability and mortality rates of up to $40 \%$ [2-15].

Chest trauma is also well known to have a significant impact on the clinical course after trauma (e.g. increased ventilation times, extended ICU stay) [9]. In this context, pulmonary injuries particularly impair lung function. The resulting pulmonary dysfunction can be exacerbated by TBIrelated interferences, such as an increased risk of aspiration or reduced defence mechanisms [8]. Further, there is evidence that even TBI alone can result in significant lung injury, likely by the induction of systemic inflammatory response syndrome (SIRS) [10].

The aforementioned aspects might explain the incidence of ventilation-associated pneumonia (VAP) of multiple trauma patients, which is four times higher than the nontrauma ICU population $[5,11]$. Due to the potentially devastating consequences of pneumonia, adequate trauma care is essential to avoid the development of post-traumatic complications [e.g. multi-organ dysfunction syndrome (MODS), acute respiratory distress syndrome (ARDS)] and adverse outcomes $[12,13]$.

However, despite the knowledge of the impact of TBI and chest trauma on the clinical course of severely injured patients, the specific relevance of these injury patterns, particularly in their combination (e.g. as independent risk factors), to the development of pneumonia and the subsequent clinical course is not fully clarified.

Therefore, it is important to investigate the relevance of TBI, chest trauma and their combination to the development of pneumonia and the subsequent effects on the development of complications and mortality. Identification of both, an injuryspecific risk profile and the impact on the clinical course might help to better prevent, diagnose and treat infections of the lung in patients with severe TBI and/or chest trauma.

\section{Materials and methods}

\section{Study design, inclusion criteria and group distribution}

A retrospective analysis of severely injured patients admitted to a level I trauma centre (Department of Orthopedic Trauma and Reconstructive Surgery, University of Aachen Medical Center, Germany) was performed. The patients were selected from our trauma database over a time period of 5 years (January 2010 until December 2015). Over the entire clinical course, clinical and radiologic records were retrieved for analysis. Further, overall length of hospital stay, stay on intensive care unit, duration of ventilation and parameters for the definition of complications were determined.

The following inclusion criteria were administered: New Injury Severity Score (NISS) $\geq 16$ and age $\geq 18$ years. Patients with incomplete data on injury severity, TBI and chest injury were excluded $(n=12)$.

According to the presence of chest and/or brain injury, we divided the included patients into four groups:

- Group poly-trauma I: Severely injured patients without TBI or chest trauma.

- Group poly-trauma II: Severely injured patients with chest trauma (without TBI).

- Group poly-trauma III: Severely injured patients with TBI (without chest trauma).

- Group poly-trauma IV: Severely injured patients with TBI and chest trauma.

\section{Injury severity and severity of traumatic brain injury and chest injury}

The overall injury severity was determined with the 2005 revised edition of the Abbreviated Injury Scale (AIS) and summarized with the NISS $[15,16]$. Traumatic brain injuries were classified according to the AIS $_{\text {head }}$ score. Patients with an $\mathrm{AIS}_{\text {head }} \geq 3$ were included in group poly-trauma III or IV. The severity of chest trauma was classified according to the AIS $_{\text {thorax }}$. An AIS thorax $\geq 3$ resulted in an inclusion in group poly-trauma II or IV. A further subdivision of chest trauma took place according to the structural injury: rib fracture, lung contusion, pneumothorax, haemothorax and tension pneumothorax.

\section{Clinical course}

All patients were managed according to the standard protocol for severely injured patients of the level I centre. Severely injured patients were first evaluated and treated in the emergency department by a trauma team according to the principles of Advanced Trauma Life Support ${ }^{\circledR}$. Radiographic diagnostics in the emergency room and therapy in the first surgical phase were performed according to the recommendations of the S3-guidelines (evidence- and consensus-based guidelines) on treatment of poly-trauma/severe injuries. 
Treatment on the ICU was also performed according to the department-specific protocols and relevant ICU guidelines.

\section{Outcome and complications}

Documented complications included ARDS, MODS and pneumonia.

ARDS was defined according to the American-European Consensus Conference on ARDS [17]. The following criteria should be fulfilled to diagnose ARDS: acute onset; oxygenation $\mathrm{paO}_{2} / \mathrm{FiO}_{2} \leq 200 \mathrm{mmHg}$ (regardless of positive end-expiratory pressure); bilateral infiltrates seen on a frontal chest radiograph; pulmonary artery wedge $\leq 18 \mathrm{mmHg}$ when measured or no clinical evidence of left atrial hypertension. MODS was classified according to the Sequential Organ Failure Assessment (SOFA) score. The SOFA score allows for calculation of both the number and the severity of organ dysfunction according to the following parameter of six organ systems: $\mathrm{PaO}_{2}, \mathrm{FiO}_{2}$, application of mechanical ventilation (respiratory), platelet count (coagulatory), bilirubin (liver), mean arterial pressure or administration of vasoactive agents (cardiovascular), creatinine or urine output (renal) and Glasgow Coma Score (GCS) (neurologic) [18, 19]. MODS was defined by an increased SOFA score of at least two organ systems. Pneumonia was diagnosed when the patient met the following criteria: new or progressive pulmonary infiltrates on a chest radiograph with fever (temperature $>38.3{ }^{\circ} \mathrm{C}$ ) or leucocytes $<4000$ cells $/ \mathrm{mm}^{3}$ or $>12,000$ cells $/ \mathrm{mm}^{3}$ and at least two of the following signs: new or changed production of purulent sputum; new or worsening dyspnoea or cough; declining oxygenation or increased oxygen requirement or need for respiratory assistance [20]. The primary outcome parameter was defined as mortality over the clinical course.

\section{Statistical methods}

Incidences are presented with counts and percentages, while continuous values are presented with the mean and standard deviations and median. Selected differences were evaluated using the Chi-squared test for counts and analysis of variance for continuous variables. The Spearman rank correlation coefficient was used to determine potential statistical associations. A two-sided $p$ value $<0.05$ was considered to be significant.

Multivariate logistic regression analysis was performed to evaluate independent predictors toward development of MODS, ARDS, pneumonia and mortality. Results were reported as odds ratio (OR) with $95 \%$ confidence intervals (95\% CI).

The data were analyzed using the Statistical Package for the Social Sciences (SPSS; version 25; IBM Inc., Somers, NY, USA).

\section{Results}

In total, 467 patients were included in this study. The overall male-female ratio was 2.6:1 with a mean age of $51.3 \pm 20.5$ years. (Table 1 ).

\section{Injury severity and severity of TBI and chest trauma}

Overall injury severity was $28.6 \pm 9.8$ points according to the NISS. Looking specifically at the severely injured patients with or without chest and/or brain injury, we found that 70 patients (15.0\%) had neither TBI nor chest trauma (poly-trauma I), 123 patients (26.4\%) sustained severe chest trauma without TBI (poly-trauma II), 196 patients (41.9\%) had severe TBI without chest trauma (poly-trauma III), and 78 patients $(16.7 \%)$ sustained severe chest trauma and severe TBI (poly-trauma IV). The incidence of pneumonia was the highest in groups with chest trauma [poly-trauma II (26.8\%) and poly-trauma IV (30.8\%)] (Table 1).

\section{Clinical course according to injury patterns and development of pneumonia}

In the analysis of the clinical course, the duration of hospital stay for all patients was $25.6 \pm 25.5$ days, the stay on ICU was $17.4 \pm 29.5$ days and the duration of ventilation was $240.4 \pm 448.3 \mathrm{~h}$. The combination of TBI and chest injury (poly-trauma IV) was associated with an increased duration of both ICU treatment $(r=0.199, p<0.001)$ and ventilation time $(r=0.171, p=0.002)$. No correlation for these parameters was found for the other trauma groups (poly-trauma I-III).

\section{Incidence of pneumonia and its association with other complications}

Over the clinical course, $19.9 \%(n=93)$ of all patients developed pneumonia, $17.6 \%(n=82)$ developed MODS and $7.3 \%(n=34)$ developed ARDS. There was a reciprocal correlation between these complications. The incidence of pneumonia was associated with the incidence of both ARDS $(r=0.555, p<0.001)$ and MODS $(r=0.176, p<0.001)$. The incidence of ARDS was correlated with the incidence of MODS $(r=0.108, p=0.022)$.

Among all observed injury patterns, increasing severity of chest trauma according to the $\mathrm{AIS}_{\text {thorax }}$ showed a correlation with the development of all three in-hospital complications, i.e. pneumonia $(r=0.164, p<0.001)$, ARDS $(r=0.113$, $p=0.017)$ and MODS $(r=0.500, p<0.001)$, but not with in-hospital mortality. The incidence of pneumonia increased independent of the type of chest injury $(r=0.176, p<0.001)$. More specifically, a correlation between haemothorax 
Table 1 Study population and characteristics according to injury distribution

\begin{tabular}{|c|c|c|c|c|c|c|}
\hline & All & $\begin{array}{l}\text { Poly-trauma I } \\
\text { (- TBI, -chest } \\
\text { injury) }\end{array}$ & $\begin{array}{l}\text { Poly-trauma II } \\
\text { (+ chest injury) }\end{array}$ & Poly-trauma III (+ TBI) & $\begin{array}{l}\text { Poly-trauma IV } \\
\text { (+TBI, + chest } \\
\text { injury) }\end{array}$ & $p$ value $^{\dagger}$ \\
\hline No. of patients (\%) & $467(100 \%)$ & $70(15.0 \%)$ & $123(26.4 \%)$ & $196(41.9 \%)$ & $78(16.7 \%)$ & - \\
\hline Age (years) & $51.3 \pm 20.5$ & $42 \pm 20$ & $49 \pm 19$ & $55 \pm 21$ & $52 \pm 20$ & $<0.001 *$ \\
\hline Gender (male) & $338(72.4 \%)$ & $54(77.1 \%)$ & $85(69.1 \%)$ & $132(67.3 \%)$ & $67(85.9 \%)$ & $<0.001 *$ \\
\hline AIS $_{\text {head }}$ & $2.6 \pm 1.9$ & $0.5 \pm 0.8$ & $0.6 \pm 0.9$ & $4.2 \pm 0.7$ & $3.7 \pm 0.8$ & $<0.001 *$ \\
\hline $\mathrm{AIS}_{\text {face }}$ & $0.6 \pm 1.0$ & $0.4 \pm 0.9$ & $0.4 \pm 0.8$ & $0.7 \pm 1.1$ & $0.7 \pm 1.1$ & $0.020 *$ \\
\hline AIS $_{\text {thorax }}$ & $1.8 \pm 1.6$ & $0.9 \pm 1.0$ & $3.4 \pm 0.7$ & $0.4 \pm 0.8$ & $3.3 \pm 0.6$ & $<0.001 *$ \\
\hline $\mathrm{AIS}_{\mathrm{abdomen}}$ & $0.7 \pm 1.3$ & $1.3 \pm 1.6$ & $1.3 \pm 1.5$ & $0.2 \pm 0.7$ & $0.7 \pm 1.3$ & $<0.001 *$ \\
\hline AIS $_{\text {extremities }}$ & $1.5 \pm 1.5$ & $2.7 \pm 1.5$ & $2.1 \pm 1.3$ & $0.6 \pm 1.1$ & $1.7 \pm 1.4$ & $<0.001 *$ \\
\hline AIS $_{\text {external }}$ & $0.4 \pm 0.9$ & $1.1 \pm 1.6$ & $0.4 \pm 0.8$ & $0.3 \pm 0.6$ & $0.3 \pm 0.6$ & $<0.001 *$ \\
\hline NISS & $28.6 \pm 9.8$ & $23.5 \pm 10.8$ & $27.5 \pm 9.7$ & $29.0 \pm 8.4$ & $33.9 \pm 10.0$ & $<0.001 *$ \\
\hline Hospital stay (days) & $25.6 \pm 25.5$ & $33.7 \pm 40.3$ & $25.9 \pm 29.2$ & $21.9 \pm 14.2$ & $24.9 \pm 14.3$ & $0.040 *$ \\
\hline ICU (days) & $17.4 \pm 29.5$ & $16.5 \pm 30.6$ & $14.6 \pm 28.0$ & $18.8 \pm 34.8$ & $19.3 \pm 15.4$ & 0.704 \\
\hline Ventilation (h) & $240.4 \pm 448.3$ & $225.6 \pm 498.5$ & $222.4 \pm 596.0$ & $234.6 \pm 300.2$ & $282.8 \pm 334.7$ & 0.878 \\
\hline Pneumonia & $93(19.9 \%)$ & $7(10 \%)$ & $33(26.8 \%)$ & $29(14.8 \%)$ & $24(30.8 \%)$ & $0.001 *$ \\
\hline ARDS & $34(7.3 \%)$ & $2(3 \%)$ & $10(9 \%)$ & $10(6 \%)$ & $12(19 \%)$ & $0.012 *$ \\
\hline MODS & $82(17.6 \%)$ & $0(0 \%)$ & $54(43.9 \%)$ & $0(0 \%)$ & $28(35.9 \%)$ & $<0.001 *$ \\
\hline Mortality & $118(25.3 \%)$ & $8(11.4 \%)$ & $18(14.6 \%)$ & $67(34.2 \%)$ & $25(32.1 \%)$ & $<0.001 *$ \\
\hline
\end{tabular}

${ }^{\dagger} p$ value indicates the overall difference between groups

*Statistical significance, $p<0.05$

( $r=0.093, p=0.049)$, lung contusion $(r=0.142, p=0.002)$ and rib fractures $(r=0.170, p<0.001)$, and the development of pneumonia was observed. The patients who developed pneumonia had a significantly higher AIS $_{\text {thorax }}$ $(2.3 \pm 1.5$ vs. $1.6 \pm 1.6, p=0.001)$, longer hospital stay [33.8 \pm 47.4 vs. $17.9 \pm 20.8, p<0.001$ (days)], longer ICU treatment $[25.9 \pm 47.3$ vs. $12.0 \pm 24.5, p<0.001$ (days)] and a longer mechanical ventilation period $[434.6 \pm 692.6$ vs. $173.8 \pm 306.9, p<0.001$ (h)]. In-hospital mortality occurred in 118 patients $(25.3 \%)$.

\section{Independent predictors for developing pneumonia}

Multivariate regression analysis of potential predictors of pneumonia showed that the duration of ventilation (OR $1.002, p<0.001)$ was an independent predictor of pneumonia. Concomitant chest injury ( $\mathrm{AIS}_{\text {thorax }} \geq 3$ ) in polytraumatized patients was also an independent predictor of pneumonia with an OR of $4.193(p=0.004)$, but the strongest independent predictor of pneumonia in polytraumatized patients was the combination of chest injury and TBI $\left(\right.$ AIS $\left._{\text {head }} \geq 3\right)$ with an OR of $4.711(p=0.004)$ (Table 2).

\section{Predictive value of pneumonia and further parameters for the development of ARDS and MODS}

The multivariate regression analysis did not show an independent predictive value of pneumonia for ARDS or MODS development. No other independent predictors for ARDS or MODS were found in this population of poly-traumatized patients.

\section{Predictive value of pneumonia and further independent predictors for mortality}

Multivariate regression analysis of potential predictors of mortality showed that pneumonia was the most powerful independent predictor of mortality with an odds ratio of $5.142(p=0.001)$. Chest trauma alone was not independently correlated with mortality. In contrast, TBI (OR $3.028, p=0.010)$ and, particularly, the combination of TBI and chest trauma (OR 3.784, $p=0.008$ ) were independent predictors for mortality (Table 3 ). 
Table 2 Multivariate regression analysis referring to pneumonia analysing age, gender, NISS, duration of ventilation, chest trauma, and TBI as potential predictors

\begin{tabular}{lcccc}
\hline Predictor & $\begin{array}{l}\text { Regression } \\
\text { coefficient }\end{array}$ & Odds ratio (OR) & $\begin{array}{l}\text { 95\% confidence } \\
\text { interval (95\% CI) }\end{array}$ & $p$ value \\
\hline Age & 0.001 & 1.001 & $0.989-1.014$ & 0.871 \\
Gender (male) & 0.296 & 1.345 & $0.747-2.422$ & 0.324 \\
NISS & -0.006 & 0.994 & $0.968-1.021$ & 0.642 \\
Duration of ventilation (per hour) & 0.002 & 1.002 & $1.001-1.002$ & $<0.001^{*}$ \\
Poly-trauma II (+ chest injury) & 1.433 & 4.193 & $1.568-11.211$ & $0.004^{*}$ \\
Poly-trauma III (+ TBI) & 0.640 & 1.896 & $0.708-5.076$ & 0.203 \\
Poly-trauma IV (+ TBI, + chest injury) & 1.550 & 4.711 & $1.644-13.499$ & $0.004 *$ \\
Constant & -2.802 & & & $<0.001$ \\
\hline
\end{tabular}

Nagelkerke $R^{2} 0.149$

*Statistical significance, $p<0.05$

\begin{tabular}{lcccc}
\hline Predictor & $\begin{array}{l}\text { Regression } \\
\text { coefficient }\end{array}$ & Odds ratio (OR) & $\begin{array}{l}\text { 95\% confidence } \\
\text { interval (95\% CI) }\end{array}$ & $p$ value \\
\hline Age & 0.032 & 1.033 & $1.021-1.045$ & $<0.001^{*}$ \\
Pneumonia & 1.637 & 5.142 & $1.924-13.739$ & $0.001^{*}$ \\
ARDS & 0.539 & 1.715 & $0.164-17.919$ & 0.652 \\
MODS & -0.139 & 0.870 & $0.405-1.870$ & 0.722 \\
Poly-trauma II (+chest injury) & 0.211 & 1.234 & $0.457-3.337$ & 0.678 \\
Poly-trauma III (+ TBI) & 1.108 & 3.028 & $1.310-7.001$ & $0.010^{*}$ \\
Poly-trauma IV (+ TBI, + chest injury) & 1.331 & 3.784 & $1.425-10.046$ & $0.008^{*}$ \\
Constant & -5.047 & & & $<0.001$ \\
\hline
\end{tabular}

Nagelkerke $R^{2} 0.220$

*Statistical significance, $p<0.05$
Table 3 Multivariate regression analysis referring to mortality analysing age, chest trauma, TBI and in-hospital complications as potential predictors in poly-traumatized patients

\section{Discussion}

The outcome after severe trauma is well known to be significantly influenced by in-hospital complications (e.g. infections, organ failure) potentially occurring over the post-traumatic clinical course. These complications were found to be associated with age, gender and overall injury severity [21-24]. Pneumonia is one of the most common complications in severely injured patients, and it is supposed to represent a predisposing factor for the development of ARDS and MODS. In this context, the studies of Vécsei [13] and Grubmüller [25] showed that chest trauma in poly-traumatized patients increased the complication rate (e.g. development of pneumonia, MODS, ARDS and sepsis) and consequently influenced the outcome. However, Chrysou et al. demonstrated that the severity of the chest trauma did not correlate with these complications [26]. Neither of these studies showed chest trauma to have an influence on mortality $[26,25,13]$. For TBI, several studies could show both a predictive value for the development of complications (e.g. pneumonia, ARDS, cardiac dysfunction, thromboembolic events, sepsis) and a significant impact on mortality [27, 14], but only one of these studies [5] addressed the combination of TBI and chest trauma as a risk factor.

Yet, the importance of TBI and chest trauma as the most common injuries in poly-traumatized patients and particularly of their combination as independent predictors for the development of pneumonia is not fully clarified. Further, it remains unclear whether the injury pattern itself or the development of pneumonia represents the most relevant risk factor for adverse outcomes (ARDS, MODS, mortality). Therefore, it is important to further elucidate these associations to enhance therapy strategies for severely injured patients [14].

The main results of the present study of severely injured patients can be summarized as follows:

- Pneumonia represents a common complication in polytraumatized patients.

- The duration of ventilation, chest injury and the combination of chest and traumatic brain injury are independent predictors for the development of pneumonia in poly-traumatized patients. 
- Pneumonia is the most powerful independent predictor of in-hospital mortality in poly-traumatized patients.

- Both TBI and the combination of TBI and chest trauma are independent predictors for in-hospital mortality in poly-traumatized patients.

\section{Impact of injury pattern on development of pneumonia}

Focusing on the different injury patterns, our finding that concomitant chest injury represents the second strongest independent predictor of pneumonia after severe trauma fully supports the results of previous studies. Grubmüller et al. found a clear correlation between severe chest injury $\left(\right.$ AIS $_{\text {thorax }} \geq 3$ ) and pneumonia in poly-traumatized patients compared to patients with mild chest injury $\left(\right.$ AIS $_{\text {thorax }}<3$ ) [25].

After subdividing the different chest injuries in all polytrauma patients, we see more specifically that haemothorax, lung contusion and costal fractures are correlating with pneumonia, which has been described in the literature before $[28,29,11,30]$. Haenel et al. [29] showed that the combination of flail chest and pulmonary contusion increased the risk of pneumonia. Mangram et al. also demonstrated that patients with rib fractures or pulmonary contusions had a more than three times greater risk of developing pneumonia than patients without these particular injuries [11]. Park et al. also showed that severe pulmonary contusion was an independent risk factor for VAP in ventilated trauma patients with multiple rib fractures [30].

In the present study, we were not able to identify TBI as an independent predictor of pneumonia. This is in contrast to other studies that described a TBI-related higher prevalence of hospital-acquired pneumonia, particularly in severely injured patients $[31,11]$. However, in the study by Mangram et al., the vast majority of the evaluated patients (77.7\%) underwent a failed pre-hospital intubation, which is a predisposing factor for the development of pneumonia [11]. In the study by Cook et al., the correlation between TBI and post-traumatic complications was based on the Glasgow Coma Scale (GCS) and not on the $\mathrm{AIS}_{\text {head }}$ as in our study [31]. The GCS in trauma patients often depends on the time of evaluation and can also change during the hospital stay in patients with severe traumatic brain injury, which might explain the different findings of our study and Cook's. Further, Hui et al. described how patients sustaining a TBI often require mechanical ventilation, and they demonstrated that this mechanical ventilation increases the risk of pneumonia in these patients, not the TBI itself [32]. This corresponds with our findings.

On the other hand, the present study shows that the combination of TBI and chest injury in poly-traumatized patients is the strongest independent predictor of pneumonia, implying that both severe TBI and severe chest injury influence the development of pneumonia. This result is supported by a study by Jovanovic et al. in which the combination of TBI and chest trauma increased the risk of the development of pneumonia [5]. Based on both the aforementioned relevance of the different injury patterns and the slightly enhanced risk profile of group poly-trauma IV (TBI + chest trauma) compared to group poly-trauma II (chest trauma) in our study, it is likely that chest trauma per se increases the risk of pneumonia; whereas, TBI exerts its effects mainly via a prolongation of mechanical ventilation.

Independent of the injury pattern, the duration of mechanical ventilation was significantly correlated with the development of pneumonia in our study. This is in line with the findings of Walaszek et al., who identified mechanical ventilation longer than 20 days as a major determinant for the development of VAP [33]. Hui et al. demonstrated in their study that each additional day of mechanical ventilation increased the risk of pneumonia by 7\% [32]. Further, another study found that mechanical ventilation was the most powerful risk factor for in-hospital infectious complications of ICU patients after trauma, such as pneumonia, urinary tract infection and ARDS [27]. The most likely reason for the high incidence of pneumonia in the trauma population is that the artificial airway, which is often required for a prolonged $(>48 \mathrm{~h}$ ) period in these patients [34,35], obliterates the natural host defences against the tracheal colonization, besides an immunity suppression induced by the injury $[5,11]$.

\section{Impact of injury pattern and pneumonia on in-hospital mortality}

Focusing on in-hospital mortality, we identified pneumonia as the strongest independent predictor of mortality. The results of previous studies on the impact of post-traumatic pneumonia on mortality are divergent. In this context, some authors found that pneumonia substantially contributes to mortality rates [36, 29, 33], whereas others did not [37, 38]. Zygun et al. [38] focused on the relevance of TBI in patients with isolated head trauma and in poly-trauma patients and found no influence of pneumonia on mortality. As we found chest injuries to be more relevant for the development of post-traumatic pneumonia, the focus on TBI in the study by Zygun et al. might result in these different findings. Rello et al. [37] described a relatively low pneumonia-related mortality rate $(3.1 \%)$ in a rather small cohort of severely injured patients $(n=161)$. As other studies with a significantly higher number of included patients (e.g. $n=1227$ [33]) also described a relevant effect of pneumonia on mortality, the size of the study population might represent an issue. Moreover, the study by Rello was performed 25 years ago, and it might be assumed that options for other potentially lethal complications (e.g. sepsis, TBI) were not as good as 
today, thereby resulting in a lower pneumonia-related mortality rate.

TBI alone is also an independent predictor of in-hospital mortality in poly-traumatized patients. The study by Yucel et al., who found an even greater odds ratio for TBI as a risk factor for mortality, strongly supports our results [39]. This result is not unexpected, as even isolated TBI is considered one of the most lethal traumatic injuries, as illustrated by the study by Para et al. [40]. Combined with a chest injury, TBI is an even stronger independent predictor of in-hospital mortality, although chest injury by itself is not an independent predictor in our study. To our opinion, this shows that TBI and chest injury are synergistic in their effect on in-hospital mortality. Our finding that severe chest injury is correlated with in-hospital complication rates in poly-traumatized patients, but has no influence on mortality rate, is supported by the results of the study of Grubmüller et al. [25]. In opposition, Chen et al. showed that patients with a higher chest trauma score had a greater prevalence of mortality [28], but this chest trauma score also included factors other than chest injuries (e.g. age). Therefore, this scoring system does not allow a conclusion to be drawn on the relevance of chest trauma as an independent factor for mortality.

\section{Impact of injury pattern and pneumonia on the clinical course}

The duration of the post-traumatic ICU stay has been found to significantly influence the clinical course and outcome, even years after the initial trauma [38, 37, 41-45]. Our finding that severe TBI is associated with an increased duration of both ICU treatment and mechanical ventilation in severely injured patients is supported by the literature. In this context, different studies, as well as the present study, have demonstrated that severe TBI usually is associated with prolonged recovery periods, prolonged stays on the ICU and longer durations of mechanical ventilation [46]. This has been explained by the fact that TBI is usually associated with injuries of other body regions and emergency surgical interventions, aggravating the patient's condition and prolonging their recovery $[2,47]$.

The results from previous studies on the effects of chest trauma on the clinical course are conflicting. Chrysou et al. [26] found that the severity of chest trauma was not associated with the length of the ICU stay, intubation days and complications, whereas others [48] found a correlation. Although we also did not find a significant effect of chest trauma on the clinical course, it seems worth noting that an additional prolongation of ICU treatment and mechanical ventilation in patients with combined TBI and chest trauma was observed in our study. This underlines the relevance of chest trauma for the post-traumatic course after severe trauma.

\section{Strengths and limitations}

The present study should be interpreted with its potential strengths and limitations. Focusing on the strengths, we did not lose patients in the follow-up period, as only in-hospital complications were assessed. In addition, the single-centre character might represent an advantage of this study as it excludes bias due to differences in treatment strategies in diverse hospitals. In contrast, this study is limited due to its retrospective design. Further, with 467 patients, the statistical results might be compromised compared to nationwide databases. Finally, the pathophysiology of in-hospital complications (e.g. MODS and ARDS) is multifactorial. However, the presented regression analyses in our study can only represent a statistical model focused on a limited number of included parameter. Diverse parameter that was not included in this study might also have a considerable impact on in-hospital complications.

\section{Conclusion}

In the present study, the most important finding is that pneumonia is the strongest independent predictor of in-hospital mortality, followed by the combination of TBI and chest injury and TBI alone. Although chest injury is not an independent predictor of mortality, it is an independent predictor of pneumonia and thereby may have an indirect influence on in-hospital mortality. The combination of chest injury and TBI is also an independent predictor of pneumonia. Chest trauma seems to represent a direct risk factor, whereas TBI acts as an indirect risk factor via a prolonged duration of ventilation, which is by itself an independent predictor of pneumonia in poly-traumatized patients. Based on our results, the development of strategies to prevent pneumonia and a prolonged ventilation period in severely injured patients should be prioritized in the clinical setting.

Author contributions $\mathrm{MH}$ designed the study, obtained the data and wrote the manuscript; HA performed the statistical analysis of the data; PK designed the study; and FH and MP reviewed the manuscript. All authors read and approved the final manuscript.

\section{Compliance with ethical standards}

Conflict of interest The authors declare that they have no competing interests.

Ethical approval All data in this study were obtained in accordance with the ethical standards of both institutional and/or national research committees and with the guidelines of the revised United Nations declaration of Helsinki in 1975 and its latest revision in 2013 (seventh revision) or comparable ethical standards. 


\section{References}

1. Dai D, Yuan Q, Sun Y, Yuan F, Su Z, Ding J, et al. Impact of thoracic injury on traumatic brain injury outcome. PLoS One. 2013;8(9):e74204. https://doi.org/10.1371/journal.pone.0074204.

2. Groswasser Z, Cohen M, Blankstein E. Polytrauma associated with traumatic brain injury: incidence, nature and impact on rehabilitation outcome. Brain Injury [BI]. 1990;4(2):161-6.

3. Kristiansen T, Lossius HM, Rehn M, Kristensen P, Gravseth HM, Roislien J, et al. Epidemiology of trauma: a population-based study of geographical risk factors for injury deaths in the workingage population of Norway. Injury. 2014;45(1):23-30. https://doi. org/10.1016/j.injury.2013.07.007.

4. Tagliaferri F, Compagnone C, Korsic M, Servadei F, Kraus J. A systematic review of brain injury epidemiology in Europe. Acta Neurochir. 2006;148(3):255-68. https://doi.org/10.1007/s0070 1-005-0651-y (discussion 68).

5. Jovanovic B, Milan Z, Djuric O, Markovic-Denic L, Karamarkovic A, Gregoric P, et al. Twenty-eight-day mortality of blunt traumatic brain injury and co-injuries requiring mechanical ventilation. Med Princ Pract Int J Kuwait Univ Health Sci Cent. 2016;25(5):435-41. https://doi.org/10.1159/000447566.

6. Khajavikhan J, Vasigh A, Khani A, Jaafarpour M, Kokhazade T. Outcome and predicting factor following severe traumatic brain injury: a retrospective cross-sectional study. J Clin Diagn Res JCDR. 2016;10(2):PC16-9. https://doi.org/10.7860/ JCDR/2016/16390.7294.

7. Asher SR, Curry P, Sharma D, Wang J, O'Keefe GE, DanielJohnson J, et al. Survival advantage and $\mathrm{PaO}_{2}$ threshold in severe traumatic brain injury. J Neurosurg Anesthesiol. 2013;25(2):16873. https://doi.org/10.1097/ANA.0b013e318283d350.

8. Evans CT, Weaver FM, Rogers TJ, Rapacki L, Miskevics S, Hahm B, et al. Guideline-recommended management of community-acquired pneumonia in veterans with spinal cord injury. Top Spinal Cord Injury Rehabil. 2012;18(4):300-5. https://doi. org/10.1310/sci1804-300.

9. Trupka A, Kierse R, Waydhas C, Nast-Kolb D, Blahs U, Schweiberer $\mathrm{L}$, et al. Shock room diagnosis in polytrauma. Value of thoracic CT. Der Unfallchirurg. 1997;100(6):469-76.

10. Vermeij JD, Aslami H, Fluiter K, Roelofs JJ, van den Bergh WM, Juffermans NP, et al. Traumatic brain injury in rats induces lung injury and systemic immune suppression. J Neurotrauma. 2013;30(24):2073-9. https://doi.org/10.1089/neu.2013.3060.

11. Mangram AJ, Sohn J, Zhou N, Hollingworth AK, Ali-Osman FR, Sucher JF, et al. Trauma-associated pneumonia: time to redefine ventilator-associated pneumonia in trauma patients. Am J Surg. 2015;210(6):1056-61. https://doi.org/10.1016/j.amjsu rg.2015.06.029 (discussion 61-2).

12. Calhoon JH, Trinkle JK. Pathophysiology of chest trauma. Chest Surg Clin N Am. 1997;7(2):199-21111.

13. Vécsei V, Arbes S, Aldrian S, Nau T. Chest injuries in polytrauma. Eur J Trauma. 2005;31(3):239-43. https://doi.org/10.1007/s0006 8-005-2033-9.

14. Mondello S, Cantrell A, Italiano D, Fodale V, Mondello P, Ang D. Complications of trauma patients admitted to the ICU in level I academic trauma centers in the United States. Biomed Res Int. 2014;2014:473419. https://doi.org/10.1155/2014/473419.

15. Osler T, Baker SP, Long W. A modification of the injury severity score that both improves accuracy and simplifies scoring. J Trauma. 1997;43(6):922-5 (discussion 5-6).

16. Baker SP, O'Neill B, Haddon W Jr, Long WB. The injury severity score: a method for describing patients with multiple injuries and evaluating emergency care. J Trauma. 1974;14(3):187-96.

17. Bernard GR, Artigas A, Brigham KL, Carlet J, Falke K, Hudson $\mathrm{L}$, et al. Report of the American-European consensus conference on ARDS: definitions, mechanisms, relevant outcomes and clinical trial coordination. The Consensus Committee. Intensive Care Med. 1994;20(3):225-32.

18. Jones AE, Trzeciak S, Kline JA. The Sequential Organ Failure Assessment score for predicting outcome in patients with severe sepsis and evidence of hypoperfusion at the time of emergency department presentation. Crit Care Med. 2009;37(5):1649-54. https://doi.org/10.1097/CCM.0b013e31819def97.

19. Vincent JL, Moreno R, Takala J, Willatts S, De Mendonca A, Bruining $\mathrm{H}$, et al. The SOFA (Sepsis-related Organ Failure Assessment) score to describe organ dysfunction/failure. On behalf of the working group on sepsis-related problems of the European Society of Intensive Care Medicine. Intensive Care Med. 1996;22(7):707-10

20. Leone M, Bouadma L, Bouhemad B, Brissaud O, Dauger S, Gibot $\mathrm{S}$, et al. Hospital-acquired pneumonia in ICU. Anaesth Crit Care Pain Med. 2018;37(1):83-988. https://doi.org/10.1016/j.accpm .2017.11.006.

21. Ingraham AM, Xiong W, Hemmila MR, Shafi S, Goble S, Neal ML, et al. The attributable mortality and length of stay of trauma-related complications: a matched cohort study. Ann Surg. 2010;252(2):358-62. https://doi.org/10.1097/SLA.0b013e3181 e623bf.

22. de Jongh MA, Bosma E, Leenen LP, Verhofstad MH. Increased consumption of hospital resources due to complications: an assessment of costs in a level I trauma center. J Trauma. 2011;71(5):E102-E109109. https://doi.org/10.1097/TA.0b013 e31820e351f.

23. Shafi S, Barnes $S$, Nicewander $D$, Ballard D, Nathens AB, Ingraham AM, et al. Health care reform at trauma centers-mortality, complications, and length of stay. J Trauma. 2010;69(6):1367-71. https://doi.org/10.1097/TA.0b013e3181fb785d.

24. Holbrook TL, Hoyt DB, Anderson JP. The impact of major inhospital complications on functional outcome and quality of life after trauma. J Trauma. 2001;50(1):91-5.

25. Grubmuller M, Kerschbaum M, Diepold E, Angerpointner K, Nerlich M, Ernstberger A. Severe thoracic trauma-still an independent predictor for death in multiple injured patients? Scand J Trauma Resusc Emerg Med. 2018;26(1):6. https://doi. org/10.1186/s13049-017-0469-7.

26. Chrysou K, Halat G, Hoksch B, Schmid RA, Kocher GJ. Lessons from a large trauma center: impact of blunt chest trauma in polytrauma patients - still a relevant problem? Scand J Trauma Resusc Emerg Med. 2017;25(1):42. https://doi.org/10.1186/s1304 9-017-0384-y.

27. Prin M, Li G. Complications and in-hospital mortality in trauma patients treated in intensive care units in the United States, 2013. Injury Epidemiol. 2016;3(1):18. https://doi.org/10.1186/s4062 1-016-0084-5.

28. Chen J, Jeremitsky E, Philp F, Fry W, Smith RS. A chest trauma scoring system to predict outcomes. Surgery. 2014;156(4):98893. https://doi.org/10.1016/j.surg.2014.06.045.

29. Haenel JB, Moore FA, Moore EE. Pulmonary consequences of severe chest trauma. Respir Care Clin N Am. 1996;2(3):401-24.

30. Park HO, Kang DH, Moon SH, Yang JH, Kim SH, Byun JH. Risk factors for pneumonia in ventilated trauma patients with multiple rib fractures. Korean J Thorac Cardiovasc Surg. 2017;50(5):34654. https://doi.org/10.5090/kjtcs.2017.50.5.346.

31. Cook A, Norwood S, Berne J. Ventilator-associated pneumonia is more common and of less consequence in trauma patients compared with other critically ill patients. J Trauma. 2010;69(5):108391. https://doi.org/10.1097/TA.0b013e3181f9fb51.

32. Hui X, Haider AH, Hashmi ZG, Rushing AP, Dhiman N, Scott $\mathrm{VK}$, et al. Increased risk of pneumonia among ventilated patients with traumatic brain injury: every day counts! J Surg Res. 2013;184(1):438-43. https://doi.org/10.1016/j.jss.2013.05.072. 
33. Walaszek M, Kosiarska A, Gniadek A, Kolpa M, Wolak Z, Dobros $\mathrm{W}$, et al. The risk factors for hospital-acquired pneumonia in the intensive care unit. Prz Epidemiol. 2016;70(1):15-20 (107-110).

34. O'Grady NP, Murray PR, Ames N. Preventing ventilator-associated pneumonia: does the evidence support the practice? JAMA J Am Med Assoc. 2012;307(23):2534-9. https://doi.org/10.1001/ jama.2012.6445.

35. Fiebich BL, Akter S, Akundi RS. The two-hit hypothesis for neuroinflammation: role of exogenous ATP in modulating inflammation in the brain. Front Cell Neurosci. 2014;8:260. https://doi. org/10.3389/fncel.2014.00260.

36. Magnotti LJ, Croce MA, Fabian TC. Is ventilator-associated pneumonia in trauma patients an epiphenomenon or a cause of death? Surg Infect. 2004;5(3):237-42. https://doi.org/10.1089/ sur.2004.5.237.

37. Rello J, Ausina V, Castella J, Net A, Prats G. Nosocomial respiratory tract infections in multiple trauma patients. Influence of level of consciousness with implications for therapy. Chest. 1992;102(2):525-9.

38. Zygun DA, Zuege DJ, Boiteau PJ, Laupland KB, Henderson EA, Kortbeek JB, et al. Ventilator-associated pneumonia in severe traumatic brain injury. Neurocrit Care. 2006;5(2):108-14.

39. Yucel N, Ozturk Demir T, Derya S, Oguzturk H, Bicakcioglu M, Yetkin F. Potential risk factors for in-hospital mortality in patients with moderate-to-severe blunt multiple trauma who survive initial resuscitation. Emerg Med Int. 2018;2018:6461072. https://doi. org/10.1155/2018/6461072.

40. Para RA, Sarmast AH, Shah MA, Mir TA, Mir AW, Sidiq S, et al. Our experience with management and outcome of isolated traumatic brain injury patients admitted in intensive care unit. J Emerg Trauma Shock. 2018;11(4):288-92. https://doi.org/10.4103/JETS. JETS_34_17.
41. Dikmen SS, Machamer JE, Powell JM, Temkin NR. Outcome 3 to 5 years after moderate to severe traumatic brain injury. Arch Phys Med Rehabil. 2003;84(10):1449-577.

42. Kesinger MR, Kumar RG, Wagner AK, Puyana JC, Peitzman AP, Billiar TR, et al. Hospital-acquired pneumonia is an independent predictor of poor global outcome in severe traumatic brain injury up to 5 years after discharge. J Trauma Acute Care Surg. 2015;78(2):396-402. https://doi.org/10.1097/TA.0000000000 000526.

43. Büki A, Czeiter E, Kovács N, Amrein K, Ezer E, Sándor J, et al. Geriatric traumatic brain injury in Hungary and Eastern Europe. Curr Transl Geriatr Exp Gerontol Rep. 2012;1(3):159-66. https ://doi.org/10.1007/s13670-012-0016-3.

44. Richards MJ, Edwards JR, Culver DH, Gaynes RP. Nosocomial infections in combined medical-surgical intensive care units in the United States. Infect Control Hosp Epidemiol. 2000;21(8):510-5. https://doi.org/10.1086/501795.

45. Wang KW, Chen HJ, Lu K, Liliang PC, Huang CK, Tang PL, et al. Pneumonia in patients with severe head injury: incidence, risk factors, and outcomes. J Neurosurg. 2013;118(2):358-63. https ://doi.org/10.3171/2012.10.JNS127.

46. Corrigan JD, Selassie AW, Orman JA. The epidemiology of traumatic brain injury. J Head Trauma Rehabil. 2010;25(2):72-80. https://doi.org/10.1097/HTR.0b013e3181ccc8b4.

47. Maas AI, Stocchetti N, Bullock R. Moderate and severe traumatic brain injury in adults. Lancet Neurol. 2008;7(8):728-41. https:// doi.org/10.1016/S1474-4422(08)70164-9.

48. Hildebrand F, Giannoudis PV, Griensven M, Zelle B, Ulmer B, Krettek C, et al. Management of polytraumatized patients with associated blunt chest trauma: a comparison of two European countries. Injury. 2005;36(2):293-302. https://doi.org/10.1016/j. injury.2004.08.012. 